\title{
Universal parameters for reporting speech outcomes in individuals with cleft palate
}

\author{
Comentado por: Lúcia Helena Ferreira Rosa ${ }^{1}$, Claudia Regina Furquim de Andrade ${ }^{2}$
}

Henningsson G, Kuehn DP, Sell D, Sweeney T, Trost-Cardamone JE, Whitehill TL; Speech Parameters Group. Universal parameters for reporting speech outcomes in individuals with cleft palate. Cleft Palate Craniofac J. 2008;45(1):1-17.

O artigo trata da apresentação de uma proposta consistente para o uso de um sistema de relatório universal para a documentação de produção de fala para indivíduos nascidos com fissura palatina. Os autores consideram que, embora existam diferentes protocolos para a avaliação da fala na população estudada, não são apresentadas medidas consistentes e de uso universal para este propósito. Essa ausência de um protocolo consensual implica perdas para as aplicações clínicas e para as pesquisas, pela impossibilidade de comparação direta dos resultados obtidos nos estudos realizados em diferentes centros e em diferentes línguas.

A primeira abordagem do artigo trata do aspecto multidisciplinar que envolve o tratamento da fissura palatina com ou sem fissura labial e considera a relevância do tratamento fonoaudiológico. Discute as diferentes abordagens sobre as medidas de fala e destaca a ausência de definições e procedimentos de amostragem consistentes. Destaca, também, que alguns autores têm maior aderência de seguidores, mas reitera que existe um leque considerável de valores de escala para classificar a severidade da hipernasalidade e alguma ressonância da avaliação de escalas, que vão de hiponasalidade a hipernasalidade. Da mesma forma, com respeito a erros articulatórios, consideram que não existe protocolo padrão de amostragem de fala ou instruções para o que constitui uma amostragem adequada de fala para capturar erros de fala que caracterizam a fissura palatina.

$\mathrm{Na}$ segunda abordagem, os autores ponderam sobre as vantagens e desvantagens de um sistema universal para relatar medidas de ocorrência de fala. Para os autores, um desafio seria o fato de que muitos clínicos têm usado um sistema particular de documentação e de relato das características de fala em suas próprias populações clínicas e poderiam relutar em mudar um sistema, considerado por eles, de sucesso. Outro desafio citado

(1) Pesquisadora do Laboratório de Investigação Fonoaudiológica da Fluência, Motricidade e Funções Orofaciais da Faculdade de Medicina da Universidade de São Paulo - USP - São Paulo (SP), Brasil.

(2) Professora Titular de Fonoaudiologia do Departamento de Fisioterapia, Fonoaudiologia e Terapia Ocupacional da Faculdade de Medicina da Universidade de São Paulo - USP - São Paulo (SP), Brasil; Coordenadora do Laboratório de Investigação Fonoaudiológica da Fluência, Motricidade e Funções Orofaciais da Faculdade de Medicina da Universidade de São Paulo - USP - São Paulo (SP), Brasil.

Endereço para correspondência: Claudia Regina Furquim de Andrade. Departamento de Fisioterapia, Fonoaudiologia e Terapia Ocupacional da FMUSP. R. Cipotânea, 51, Cidade Universitária, São Paulo - SP, CEP: 05360160. E-mail: clauan@usp.br seria a incorporação de medidas que sejam verdadeiramente universais, a despeito de diferenças de estrutura fonética entre as línguas, que poderiam ter efeito diferencial nas medidas que estariam sendo avaliadas.

Diante disso, os autores entram na proposta do trabalho: desenvolver um sistema universal explícito de relato de medidas perceptuais de ocorrência importante na fala, tipicamente obtidas para pessoas nascidas com fissura palatina, independente do país de origem, da língua ou das línguas faladas e outras variáveis que possam afetar o comportamento da fala do indivíduo. O objetivo é alcançar maior consistência no relato de ocorrências de fala baseado em parâmetros que possam ser usados globalmente. Na proposta, a avaliação perceptual permanece como um padrão ouro para a avaliação da fala, sendo o método mais comumente usado.

Inicia-se, então, um histórico do projeto. O relato é de que o trabalho evoluiu a partir de encontros em diversos eventos da área, sendo o primeiro deles o $7^{\circ}$ Congresso Internacional de Fissura Palatina e Anomalias Crânio Faciais, realizado em Broadbeach, Queensland, Austrália em 1993. Desde então, o trabalho do grupo foi evoluindo e culminou com uma proposta centrada em três núcleos: informações de identificação do paciente; amostragem de fala; definição e descrição de parâmetros.

Sobre as informações de identificação do paciente são pormenorizados os aspectos relevantes sobre cada paciente. Essa informação é importante em relação a possíveis características de pacientes e procedimentos de avaliação que poderiam impactar o relatório de ocorrência de fala. Sobre esse tópico é apresentado um formulário base.

Em relação à amostragem de fala, são detalhados os aspectos da avaliação da fala, nas diferentes situações, para investigar consistência e frequiência de erros, e representatividade da amostragem de informações. Com isso, são investigados diversos parâmetros em contextos de fala controlados, tais como: repetição de sentenças, contextos naturais e fala espontânea. Os autores ressaltam que, no entanto, para comparar informações de ocorrências de fala entre línguas diferentes, a influência diferencial da língua deve ser eliminada, isto é: somente estímulos de som de fala foneticamente similares devem ser usados na construção da amostragem de fala em cada língua. Esse aspecto do artigo é bastante construtivo, pois destaca a importância de seguir princípios específicos para a construção da amostragem de fala. Teoricamente, comparações interlinguísticas de ocorrência de fala requerem um núcleo 
de grupo de sons comuns a todas as línguas. A validação de tais comparações seria aumentada por meio da comparação de apenas sons de fala foneticamente idênticos ou ao menos similares entre línguas. Comparando sons de fala idênticos ou similares que sejam particularmente vulneráveis, a produção de erro aumentaria a probabilidade de esses erros serem relativos à presença da fissura e não pelas características especificas da língua falada.

Consoantes de alta pressão e vogais altas são bem documentadas como sons de fala vulneráveis para indivíduos com fissura palatina. Para os autores, o conhecimento destes sons de fala constitui parte do inventário de alguns sons de todas as línguas. Por isso eles poderiam ser considerados como universais e adequados para a construção de amostragem de fala, independente da língua falada pelo paciente. Portanto, para comparar com validade ocorrências de fala entre línguas, princípios comuns para a construção de amostra de fala, em particular envolvendo estes sons, poderiam ser usadas. Os autores detalham um estudo multicêntrico em andamento (http://www.eurocran.org) sobre o assunto.

Sobre a definição e descrição de parâmetros, os autores consideram que cinco parâmetros seriam de consenso universal para o relato de ocorrência da fala na fissura palatina: hipernasalidade, hiponasalidade, emissão de ar nasal e/ou turbulência, erros na produção de consoantes e problemas de voz. Além desses, também são considerados como parâmetros globais: o entendimento e aceitação da fala dos indivíduos fissurados por eles mesmos e pelos interlocutores. O assunto é tratado no texto de forma aprofundada e bastante esclarecedora, com protocolos e definições precisas sobre o assunto.

$\mathrm{Na}$ finalização do texto, os autores discutem sobre o plano desenvolvido para documentar ocorrências de fala em indivíduos com fissura palatina, independente da língua falada, usando um conjunto de cinco parâmetros em um relatório universal. Ponderam sobre as vantagens do uso desse sistema como um projeto útil para converter aquilo que, em alguns casos, são dados altamente detalhados de uma avaliação local para um conjunto de parâmetros controláveis e compreensíveis com o propósito comum de constituir um relatório. Isto é, quanto maior o numero de detalhes e a complexidade de vários sistemas, mais difícil fazer comparações entre os dados obtidos por estes grupos. A proposta dos autores foi obter os parâmetros mais salientes que pudessem ser mapeados e permitissem comparações entre conjuntos de dados. Os autores consideram, ainda, a colaboração do projeto como estímulo para a modificação das ações terapêuticas e melhora no sistema de avaliações quanto a sua validade e confiabilidade. Também consideram positiva a contribuição para que haja uniformidade terminológica, já que a proposta apresenta definições específicas, ressaltando os termos descritivos que caracterizam a fala de indivíduos fissurados. Para os autores, se esses termos forem adotados e usados de maneira consistente, de acordo com as definições fornecidas, haverá maior produtividade comunicativa entre os profissionais.

Outra contribuição de destaque do artigo é a importância da padronização da amostra de fala, usada de maneira controlada, para que forneça maiores detalhes sobre os desvios de fala característicos de indivíduos que foram submetidos à cirurgia reparatória da fissura.

Os autores reconhecem as limitações e desafios associados ao projeto proposto. Para eles, um desafio importante envolve a coleta de dados para o estágio de relatório, isto é, a avaliação dos dados das equipes locais. Questões sobre a validação e confiabilidade nas avaliações, serão, sempre, um fator determinante na qualidade de qualquer projeto de estudo. Satisfazer as questões de validade e confiabilidade na coleta de dados depende, necessariamente, da proficiência dos membros da equipe local e da adoção e uso de uma amostra de fala apropriadamente construída.

Outro destaque dos autores diz respeito à quantificação, um mecanismo de pontuação da severidade. O mecanismo de pontuação poderia ser estruturado de forma que fosse estabelecida uma pontuação de produção total (parâmetros de pontuação universal e parâmetros de pontuação global) bem como pontuações separadas para parâmetros universais e globais. Isto permitiria várias combinações de medidas que poderiam ser correlacionadas umas com as outras para comparação estatística. Por exemplo, a pontuação total dos cinco parâmetros poderia ser comparada com as medidas globais ou entre si. O sistema de pontuação poderia ser confrontado tanto com as medidas quantitativas como qualitativas que foram obtidas em diferentes centros de fissura de lábio e palato, em diferentes países.

O artigo contribui, significativamente, para a adoção de parâmetros universais para que possam ser comparados atributos específicos das alterações que são e que não são determinados pela influência da língua. É um estudo relevante. 